\title{
Influence of Fiber Content on Mechanical and Morphological Properties of Woven Kenaf Reinforced PVB Film Produced Using a Hot Press Technique
}

\author{
Suhad D. Salman, ${ }^{1,2}$ Z. Leman, ${ }^{1}$ M. T. H. Sultan, ${ }^{3}$ M. R. Ishak, ${ }^{3,4}$ and F. Cardona ${ }^{3}$ \\ ${ }^{1}$ Department of Mechanical and Manufacturing Engineering, Faculty of Engineering, Universiti Putra Malaysia, \\ 43400 Serdang, Selangor, Malaysia \\ ${ }^{2}$ Materials Engineering Department, Faculty of Engineering, Al-Mustansiriya University, Baghdad, Iraq \\ ${ }^{3}$ Aerospace Manufacturing Research Centre (AMRC), Level 7, Tower Block, Faculty of Engineering, Universiti Putra Malaysia, \\ 43400 Serdang, Selangor, Malaysia \\ ${ }^{4}$ Laboratory of Bio-Composites Technology, Institute of Tropical Forestry and Forest Products (INTROP), \\ Universiti Putra Malaysia (UPM), 43400 Serdang, Selangor, Malaysia
}

Correspondence should be addressed to Suhad D. Salman; suhaddawood2007@yahoo.com

Received 3 December 2015; Accepted 27 January 2016

Academic Editor: Heitor L. Ornaghi

Copyright (C) 2016 Suhad D. Salman et al. This is an open access article distributed under the Creative Commons Attribution License, which permits unrestricted use, distribution, and reproduction in any medium, provided the original work is properly cited.

\begin{abstract}
This work addresses the results of experimental investigation carried out on mechanical and morphological properties of plain woven kenaf fiber reinforced PVB film which was prepared by hot press technique. The composites were prepared with various fiber contents: $0 \%, 10 \%, 20 \%, 30 \%, 40 \%, 50 \%$, and $60 \%$ (by weight), with the processing parameters $165^{\circ} \mathrm{C}, 20 \mathrm{~min}$, and at a pressure of $8 \mathrm{MPa}$ applied on the material. Tensile, flexural, and Charpy impact properties were studied as well as morphological properties of impact fracture surface. With the increase in kenaf fibers content up to $40 \%$, the PVB composites have shown lower tensile and flexural strength accompanied with reduction in the ultimate strain of the composite. The results showed that impact properties were affected in markedly different ways by using various kenaf contents and decrease with the increase in kenaf fiber content up to $40 \%$; however, high impact strength was observed even with $40 \%$ kenaf fiber content. Furthermore, scanning electron microscopy for impact samples was utilised to demonstrate the different failures in the fracture surfaces for various kenaf fibers contents.
\end{abstract}

\section{Introduction}

Natural fiber composites are proposed to replace synthetic materials in many engineering applications due to several advantages such as renewability, less abrasiveness to equipment, biodegradability, and low weight and cost [1]. Kenaf fiber has been found to be an important source of fiber for composites due to its good properties and its contribution to environmental sustainability and eco-friendly products $[2,3]$.

In several studies, El-Shekeil et al. [4-6] have concentrated their efforts on the study of the natural fiber content effects on the behavior of composites. It was concluded that the fiber content strongly affects the overall properties of composites; $30 \%$ fiber loading displays the best tensile strength, while the tensile modulus, thermal stability, hardness, and flexural strength increased with increase of fiber content, but the strain decreased. In other studies, Joseph et al. [7] and Ku et al. [8] described a remarkable increment of mechanical behaviors in the polymeric composites by increasing the natural fiber content.

Likewise, Ochi [9] and Nishino et al. [10] indicated that unidirectional kenaf/polylactic acid composite at fiber loading of $70 \%$ has high tensile and flexural strength. It was concluded that the decline in tensile strength and Young's modulus increased with the increase of fiber loading with above 70 vol.\%. This means fibers might not be fully saturated because of insufficient filling of the polymer amount. Similarly, Lee et al. [11] investigated the kenaf/polypropylene 
composites fabricated with different fiber content, varying from $10 \%$ to $70 \%$ weight fraction with $10 \%$ increment. The results indicated that the tensile strength and modulus of kenaf/PP composites increased with increasing kenaf fiber contents, reaching a maximum value at $40 \%$, and then decreased.

However, Hargitai et al. [12] indicated that the mechanical behaviors of the hemp/PP composites improved when the hemp fiber content increased, up to $50 \%$, and reduced gradually at 70\%. Shibata et al. [13] examined the flexural behavior of the kenaf fiber reinforced biodegradable resin composites and observed that flexural modulus increases with increase in kenaf loading irrespective of fiber orientation. This is in agreement with the findings of Liew [14] who found similar trends for oil palm fiber/polyester composites and concluded that the presence of $40 \%$ fiber content is the best. Rao et al. [15] studied experimentally the effect of banana fiber loading and other natural fibers reinforced polyester composites on mechanical behaviors of their composites.

More recently, a few attempts have been made to study the effect of processing method and polymer type relative to the physical and mechanical properties of composites based on kenaf fibers by Sharba et al. [16, 17]. From the results, it was concluded that kenaf fibers could be used as a potential reinforcing material, in order to decrease the use of synthetic fibers while taking advantage of natural resources.

However, the experimental results are different due to the properties of fibers and viscosity of matrix; therefore, the effect of fiber loading on the mechanical behavior of composites is one of the significant interests of many researchers. Even though many studies in the literature investigate the fiber loading effects on mechanical characterization, introducing new resin into the field of natural fiber composites gives more alternatives with a broad set of properties. Kenaf reinforced PVB film composites will open a new avenue for use in structural applications due to their remarkable properties, for example, in the automotive and aircraft industries. The objective of this research is to study the effect of fiber content on the mechanical performance of plain woven kenaf reinforced PVB composite.

\section{Materials and Methods}

To clarify the effect of fiber loading on the mechanical behavior of composites, plain woven kenaf and PVB film were utilised to fabricate the composites with different kenaf fiber loading. Plain woven kenaf was supplied by ZKK Sdn. Bhd., Malaysia, with the properties as reported in Table 1 and shown in Figure 1. PVB film (polyvinyl butyral resin) is now employed in a wide array of industrial processes and projected to ascertain a bright future for the new industry. The PVB tensile strength is $\geq 20 \mathrm{MPa}$ and breaking elongation $\geq 200 \%$ (manufacturer data sheet).

2.1. Fabrication of Composite Samples. The composite samples were made with $10 \%, 20 \%, 30 \%, 40 \%, 50 \%$, and $60 \%$ kenaf fiber weight content by using a hot hydraulic press technique to reinforce PVB film. A detailed flow chart for
TABLE 1: Properties of woven kenaf [18].

\begin{tabular}{lc}
\hline Characterization & Woven kenaf \\
\hline Thickness, $t(\mathrm{~mm})$ & $2 \pm 0.2$ \\
Weight $\left(\mathrm{g} / \mathrm{m}^{2}\right)$ & 890 \\
Density $\left(\mathrm{g} / \mathrm{cm}^{3}\right)$ & 1.2 \\
Warp density (warp/inch) & 12 \\
Weft density (weft/inch) & 12 \\
Wavelength, $\lambda(\mathrm{mm})$ & 4.2 \\
Interyarn fabric porosity $(\varepsilon)$ & 0.274 \\
Moisture content $(\%)$ & 8.353 \\
Water uptake $(\%)$ & 148.86 \\
Average breaking strength $(\mathrm{MPa})$ & 100.64 \\
Average maximum strain $(\%)$ & 17.3 \\
\hline
\end{tabular}

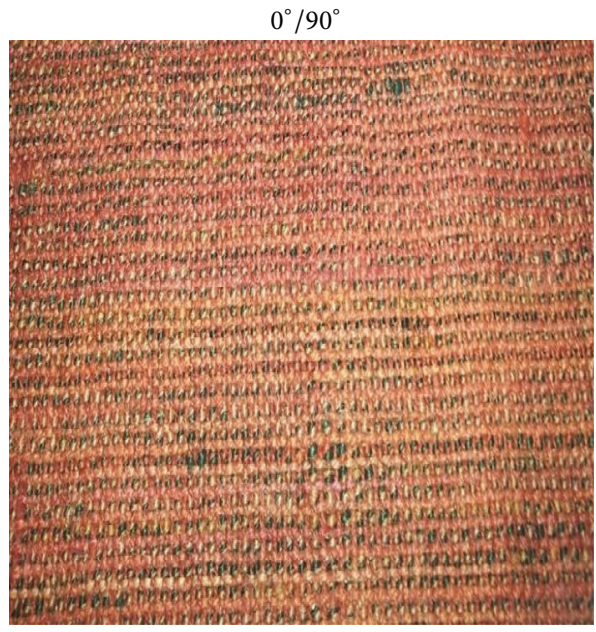

Figure 1: Kenaf fiber.

processing method is explained in Figure 2. Six panels with dimension $300 \mathrm{~mm}$ by $300 \mathrm{~mm}$ were fabricated and then cut by using a wheel saw machine, according to the ASTM standard of each test. For each panel, five layers of woven kenaf and six layers of PVB film are centered between two stainless-steel molds and hot plates of a compression moulding press. The hot press plates are heated to $165^{\circ} \mathrm{C}$ and the compression pressure is increased to $8 \mathrm{MPa}$ and held constant for $15 \mathrm{~min}$. Then, the platen temperature is reduced to room temperature $\left(25^{\circ} \mathrm{C}\right)$, under pressure $8 \mathrm{MPa}$, until the temperature reaches $25^{\circ} \mathrm{C}$. The panel was taken out of the compression molding frame and allowed to complete inner cure.

2.2. Mechanical Properties of Composites. The effect of fiber content on the tensile and flexural properties of woven kenaf/PVB composites was investigated in the composite laboratory of the Mechanical Department, Universiti Putra Malaysia, according to the ASTM D3039/D3039M-10 [19] and ASTM D790-10 [20]. The composites were categorized according to their fiber weight fractions (10\%, 20\%, 30\%, $40 \%$, and $50 \%$ ). The test was carried out to determine the maximum tensile strength, maximum tensile strain, tensile 

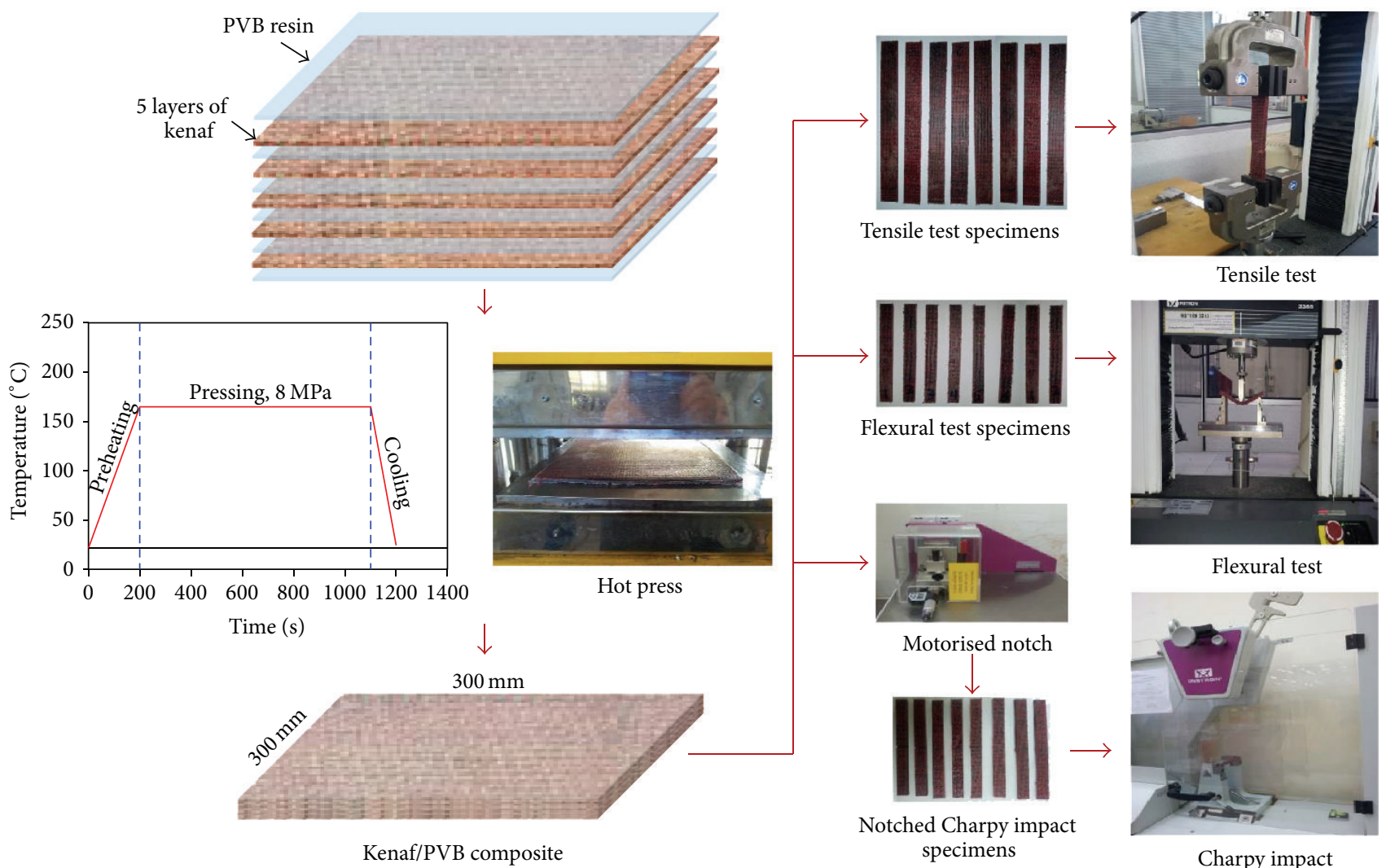

FIGURE 2: Drawing of the plain woven kenaf/PVB composite laminates by using the hot press technique and the temperature profile.

modulus, and stress-strain graphs, with crosshead speed of $1 \mathrm{~mm} / \mathrm{min}$. Tensile specimens were cut to $250 \mathrm{~mm} \times 25 \mathrm{~mm}$ $\times$ actual thickness for each composite, rectangular sectional area flat strip (gage length of $170 \mathrm{~mm}$ ). Four tabs plates with a dimension of $40 \times 25 \mathrm{~mm}$ were attached to the two sides of both ends of the specimens by an adhesion agent.

The flexural tests were investigated using the three-point bending fixture with rectangular shape three-point bending specimens, $127 \mathrm{~mm} \times 12.7 \mathrm{~mm} \times$ actual thickness for each composite. The distance between the supports (span length) was calculated as per the standard, with a ratio of $16: 1$. The crosshead motion was calculated for each composite, according to

$$
R=\frac{Z \times L^{2}}{6 \times d},
$$

where $R$ is rate of crosshead motion ( $\mathrm{mm} / \mathrm{min}), L$ is support span (mm), $d$ is depth of composite ( $\mathrm{mm}$ ), and $Z$ is equal to 0.01 .

The flexural modulus or bending modulus was calculated by drawing a tangent to the steepest initial straight-line portion of the stress-strain curve and using

$$
E_{b}=\frac{L^{3} m}{4 b d},
$$

where $E_{b}$ is the modulus of elasticity in bending $(\mathrm{MPa}), m$ is the slope of the tangent to the initial straight-line portion of the load-deflection curve, $(\mathrm{N} / \mathrm{mm})$ of deflection, and $b$ is the width of sample tested $(\mathrm{mm})$.

Eight samples for each composite were tested and the average value of five specimen results was reported by using a universal testing machine (Instron 3365) with a capacity of $100 \mathrm{KN}$ (for both tests).

The impact strength of the samples was measured using Charpy impact test machine, according to the ASTM D6110 [21]. The Charpy impact tests were conducted by using a universal testing machine, INSTRON, MECOMB, in the Laboratory of Bio-Composites Technology, Institute of Tropical Forestry and Forest Products (INTROP), Universiti Putra Malaysia. By using a wheel saw machine, the specimens were carefully cut and finished to the accurate size, $127 \mathrm{~mm} \times$ $12.7 \mathrm{~mm} \times$ actual thickness for different weight fraction and striking hammer energy $(0.5,2.7,5.4$, and 21.6 joules). All impact test samples were notched with the radius of curvature $0.25 \mathrm{Rm}$ to $2.54 \mathrm{~mm}$ by motorised Notchvis in the middle. Eight specimens for each composite and energy level were tested and the average value of five specimen results was reported.

2.3. Morphological Observation. The influence of the kenaf fiber content on the fractured surface of the composites after Charpy impact test was observed by using the scanning electron microscope (SEM) instrument model Hitachi $5.00 \mathrm{kV}$, 


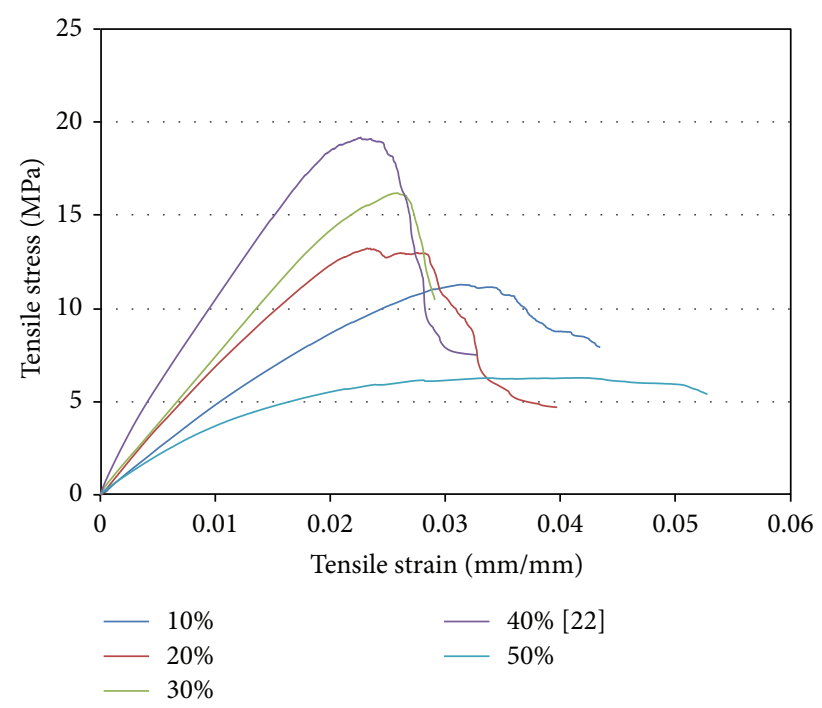

FIgURE 3: Average values of tensile stress-deformation diagram of different fiber content of kenaf/PVB composites.

after being coated with a thin layer of gold to avoid electron charge accumulation.

\section{Results and Discussions}

3.1. Tensile Test Results. Figure 3 shows that the stress-strain curve of kenaf/PVB film with different fiber content is linear and follows Hooke's law. It could be seen that the tensile strength increased linearly with the increase of the tensile strain and fiber content, reaching a maximum value at $50 \%$. However, when it reaches certain stress values, nonlinear behavior is noticed, especially for the $10 \%$ and $50 \%$ fiber content. The average tensile strength is $11.28 \mathrm{MPa}, 13.23 \mathrm{MPa}$, $16.19 \mathrm{MPa}, 19.19 \mathrm{Mpa}$, and 6.27 MPa for 10\%, 20\%, 30\%, 40\% [22], and 50\% fiber content, respectively. The results indicated that failure takes place at a much lower strain rate at 30\% and $40 \%$ kenaf fiber content. Meanwhile, the highest tensile strength was enhanced at $40 \%$ kenaf fiber content. The results indicated that the mechanical interlocking was sufficient to transfer the load from the PVB film to the kenaf fibers and the reinforcing effect of the kenaf fibers predominated, while at low kenaf fiber content, less fiber amount caused low load transfer capacity among the fibers, which led to accumulation of stress that occurred in the matrix which led to rapid failure of the composites. The low stress rate for 50\% fiber content is attributed to two reasons. The first reason is the low tensile properties of PVB film, and the second one is the fact that the spacing between kenaf fibers becomes so small that the stress transfer between kenaf fiber and PVB resin becomes inefficient. As a result, a premature failure occurred due to increased shear stresses on all planes parallel to the axes of the fibers which led to delamination. It is stated by Kim et al. [23] that most highly polymeric materials tend to be stress rate dependent. It has been recorded that the strength of composites is influenced by several factors such as fiber content, fiber/matrix interfacial bonding, and fiber

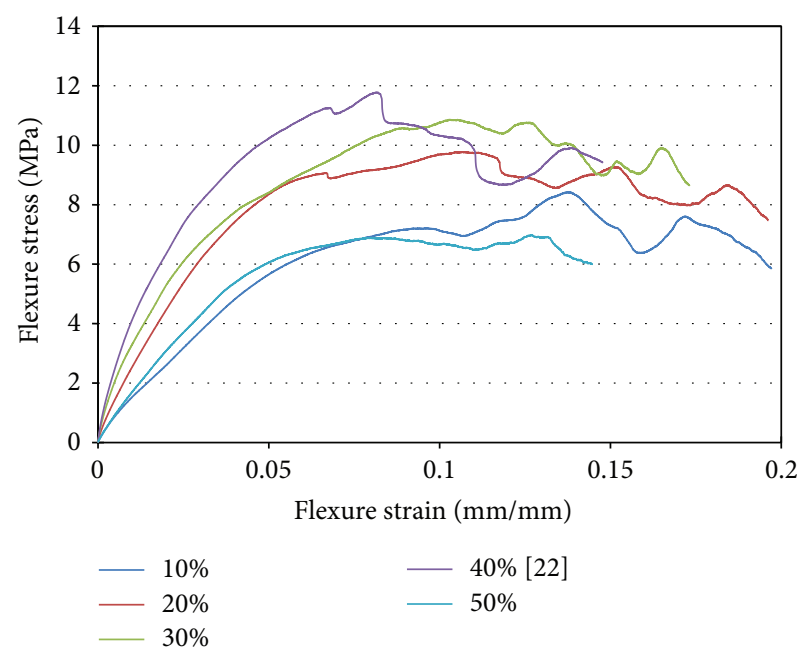

FIGURE 4: Effect of different kenaf fiber content on flexural properties of kenaf/PVB composites.

and matrix strength [24]. However, the fiber works as load carriers in the matrix, and high tensile strength depends more on effective and uniform stress distribution. Several researches have concluded that there is a practical maximum fiber content above which composite characteristics deteriorate $[25,26]$ and/or porosity increases highly [27]. Similar findings were also observed by $\mathrm{Ku}$ et al. [8], who reported that the increment of fiber loading above $40 \%$ causes the reduction in ultimate strength.

3.2. Flexural Test Results. Flexural characteristics represent the flexibility of the materials and good flexural strength indicates that the materials have brittle properties and high hardness [4]. Figure 4 shows the effect of different fiber content on the flexural properties of kenaf/PVB composites. Flexural strength behaved with a similar trend to tensile strength behavior; the $40 \%$ kenaf fiber content has the highest stress to resist deformation under flexural condition. As a result of good interfacial bonding between kenaf fiber and PVB film, the fibers are effectively participating in the stress transfer. Tensile, compression, and shear stresses caused the flexural failure that occurred at the two sides of the bending samples [28]. The average flexural strength is $8.4 \mathrm{MPa}, 9.8 \mathrm{MPa}, 10.8 \mathrm{MPa}, 11.8 \mathrm{MPa}$, and $6.98 \mathrm{MPa}$ for $10 \%, 20 \%, 30 \%, 40 \%$, and $50 \%$ fiber content, respectively. A characteristic stepwise reduction in flexural stress was demonstrated with increasing both the strain of maximum flexural stress and up to $40 \%$ kenaf fiber content. Hence, the failure in flexural testing of the kenaf/PVB film is dominated by individual ply failure rather than any observable interlaminar failure. It can be concluded that $40 \%$ kenaf fiber content exhibited relatively high flexural strength; good kenaf fiber/PVB bonding offers an advantage over other composites. The comparatively lower flexural modulus of the $50 \%$ kenaf fiber content is due to using lower percentage of PVB film, which might lead to inefficient load transfer from fiber to matrix (weak fiber adhesion). As reported in 


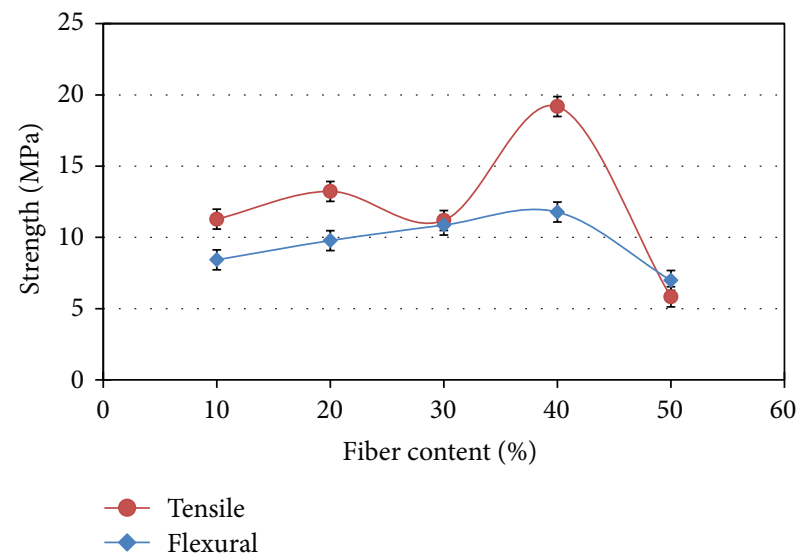

(a)

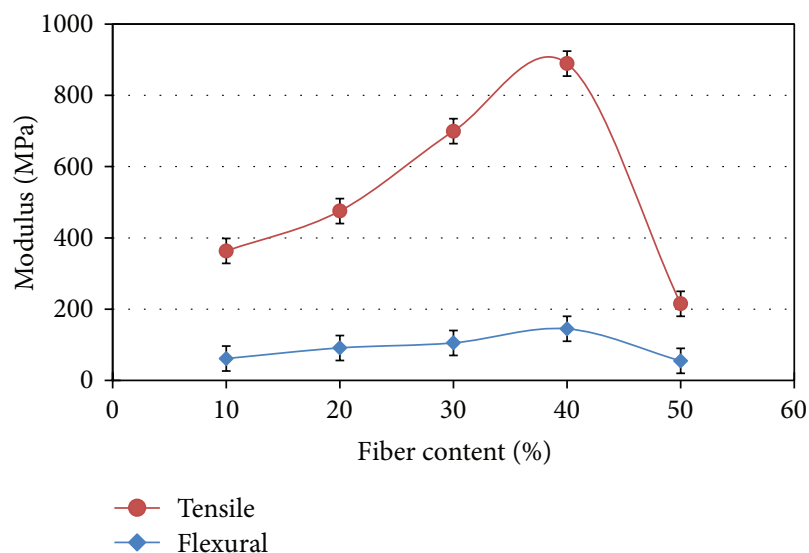

(b)

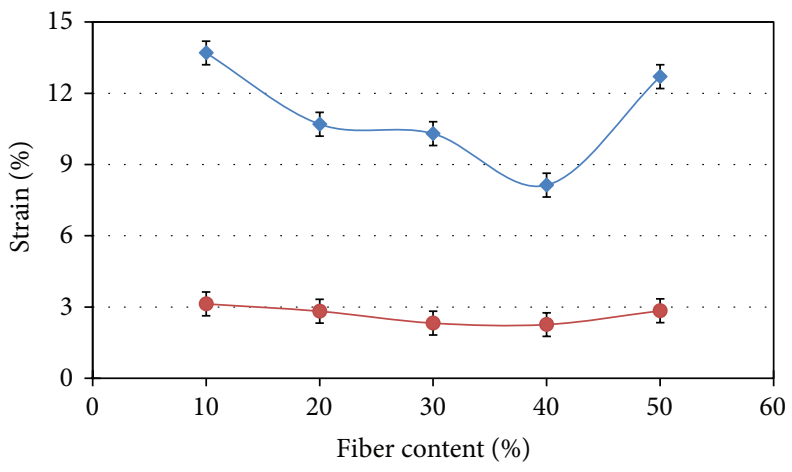

- Tensile

Flexural

(c)

FIgURE 5: Comparison of (a) tensile and flexural strength with kenaf fiber content, (b) tensile and flexural modulus with kenaf fiber content, and (c) tensile and flexural strain with kenaf fiber content.

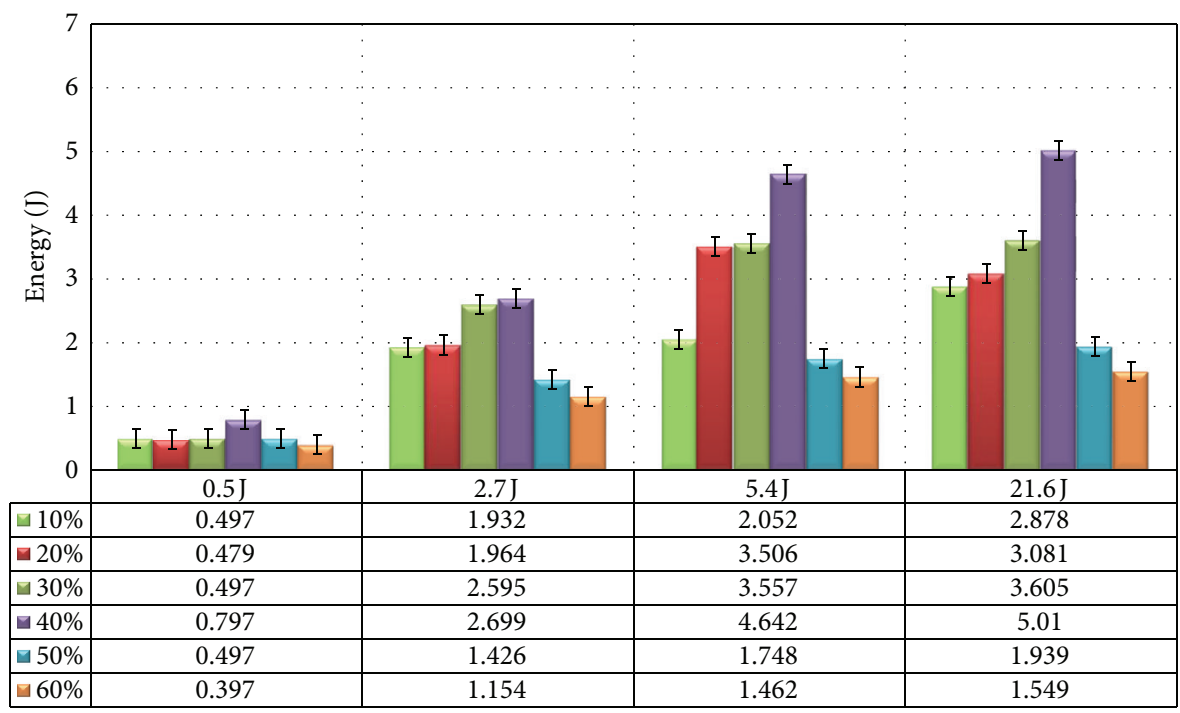

FIGURE 6: Effect of fiber content on impact energy of kenaf/PVB composites at different energy levels. 
previous studies, the flexural strength increased at the $40 \%$ fibers content $[13,29]$, the stiffer and higher to resist any deformation.

Figures 5(a), 5(b), and 5(c) show the effects of fiber content on the average tensile and flexural strength, modulus, and strain of the kenaf fiber reinforced PVB composites, respectively. In Figure 5(a), it is noticed that the tensile and flexural strength are increasing gradually with increase in fiber content up to $40 \%$ kenaf content and then decreased. Similarly, de Albuquerque et al. [30] have reported the same trend on the Jute reinforced polyester composites. Figure 5(b) shows that the modulus increased with addition of fibers, reaching a maximum value at $40 \%$ kenaf content, and then reduced. As discussed earlier, a lower value for tensile and flexural modulus is predominantly seen for $50 \%$ kenaf content composites due to increased shear stresses on all planes parallel to the axes of the fibers. The tensile modulus is 363.5 MPa, 475.5 MPa, 699.4 MPa, 889.2 $\mathrm{MPa}$, and 215.3 MPa for $10 \%, 20 \%, 30 \%, 40 \%$, and $50 \%$ fiber content, respectively, while flexural modulus is $61.497 \mathrm{MPa}, 91.4 \mathrm{MPa}, 105.5 \mathrm{MPa}$, $144.9 \mathrm{MPa}$, and $54.98 \mathrm{MPa}$ for $10 \%, 20 \%, 30 \%, 40 \%$, and $50 \%$ fiber content, respectively. The tensile and flexural strain show an inverse relationship to strength and modulus. As illustrated in Figure 5(c), when kenaf fiber content was increased until 30\%, failure took place at the lowest strain rate. It can be indicated that the strain is decreasing with increase in fiber content, up to $30 \%$ fiber content. The tensile strain is $3.13 \%, 2.82 \%, 2.32 \%, 2.26 \%$, and $2.84 \%$ for $10 \%, 20 \%$, $30 \%, 40 \%$, and $50 \%$ fiber content, respectively. The value of the maximum tensile strain decreased slightly for $40 \%$; nevertheless, flexural strain increased for $50 \%$ continuously (12.7\%). In the $10 \%$ kenaf fiber content composite, insufficient fibers are mixed with large PVB matrix; thus, elongation will be high because it is high in the PVB matrix. At $30 \%$ kenaf fiber content composite, more kenaf fibers were there which could transfer stress properly along them, leading to less elongation. This prevents creating a crack propagation rate, thus causing the composite to break at a higher failure strain. Both fibers content and characteristics of individual reinforcing fibers are the main factors which have affected the variation in the modulus and failure strain of composites.

3.3. Impact Test Results. Figure 6 compares the energy absorption capability of the different kenaf fiber content under varied impact energies, $0.5 \mathrm{~J}, 2.7 \mathrm{~J}, 5.4 \mathrm{~J}$, and $21.6 \mathrm{~J}$, respectively. It showed the variation of the energy absorbed by the tested specimens under different energies levels. However, the Charpy impact energy of different kenaf content showed almost the same behavior when tested under the same energy level. It could be observed that there is an increase in the total energy absorption by the specimens up to $40 \%$ then a decrease was observed. The level of maximum impact energy reached for the $40 \%$ kenaf/PVB composite is the highest value at different energy levels. At low energy level, $0.5 \mathrm{~J}$, there is not a significant difference in the absorbed energy that can be observed for the various kenaf fiber contents. However, when the energy level was increased, a high increment in the absorbed energy can be seen for kenaf/PVB composite

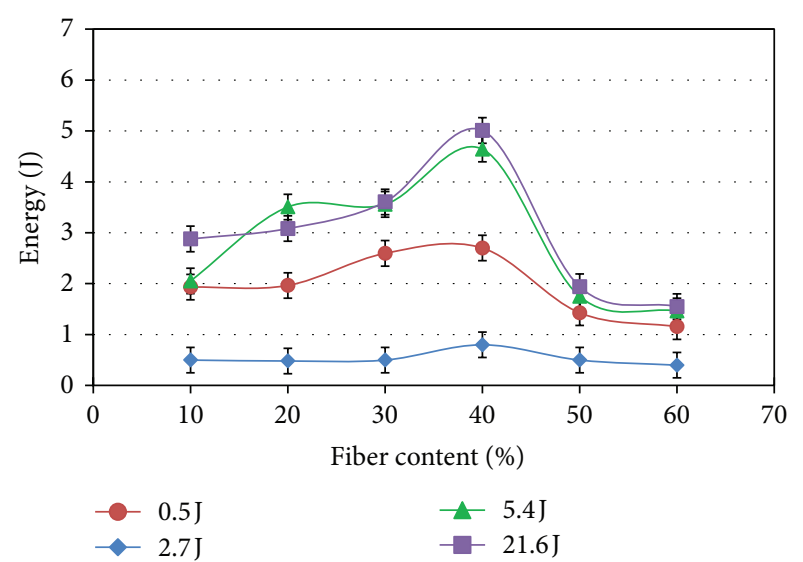

Figure 7: Effect of fiber content on impact energy of kenaf/PVB composites at different energy levels.

up to $40 \%$ kenaf fiber content, as shown in Figure 7. Then, the energy absorbed is decreased at $50 \%$ and $60 \%$ kenaf fiber content, at different energy levels. Due to the lower percentage of resin, both intralayer failures and delamination affect the total absorbed energy values at these kenaf fiber contents, which is found to change the failure mechanism of the composites [31]. However, the amount and the type of failure mechanism depend on the impact energy level and mechanical properties of fiber and matrix [32].

A similar finding was also observed in the average impact strength of the kenaf/PVB composites with different kenaf content and energy levels, as shown in Figure 8. It was clear that, for the composite specimens with $40 \%$ kenaf fiber content, higher values of impact strength were recorded compared with the other composites, at different energy levels. This is attributed to the fact that the increase of fiber content above $40 \%$ causes lack of energy absorbance. It could be attributed to the increase of the stiffness of the composite by increase of fiber content to reinforced thermoplastics, as reported by Joffe and Andersons [33]. Generally, it can be seen that the impact energy strongly depends on the percentage of the fiber content, especially when combining natural fibers with thermoplastics [34, 35], as shown in Figure 9. Further, low interface shear stress between natural fiber and polymer resin might contribute to the increase in the composite strength. The incorporation of lignocellulosic fibers offers an obstacle to the propagation of an initial crack at the specimen notch and then causes other cracks at the weak fiber/matrix interface to propagate longitudinally through the interface following the specimen length direction. Likewise, Wirawan et al. [36] have reported that higher absorbed impact energy resulting in corresponding higher strength of sugarcane reinforced PVC thermoplastic.

Similarly, the Charpy impact toughness seems to have the same impact energy and impact strength behaviors at different energy levels, as represented in Figures 10 and 11. It is clearly seen that the composite materials with $40 \%$ kenaf fiber content have the greatest impact toughness value, at different 


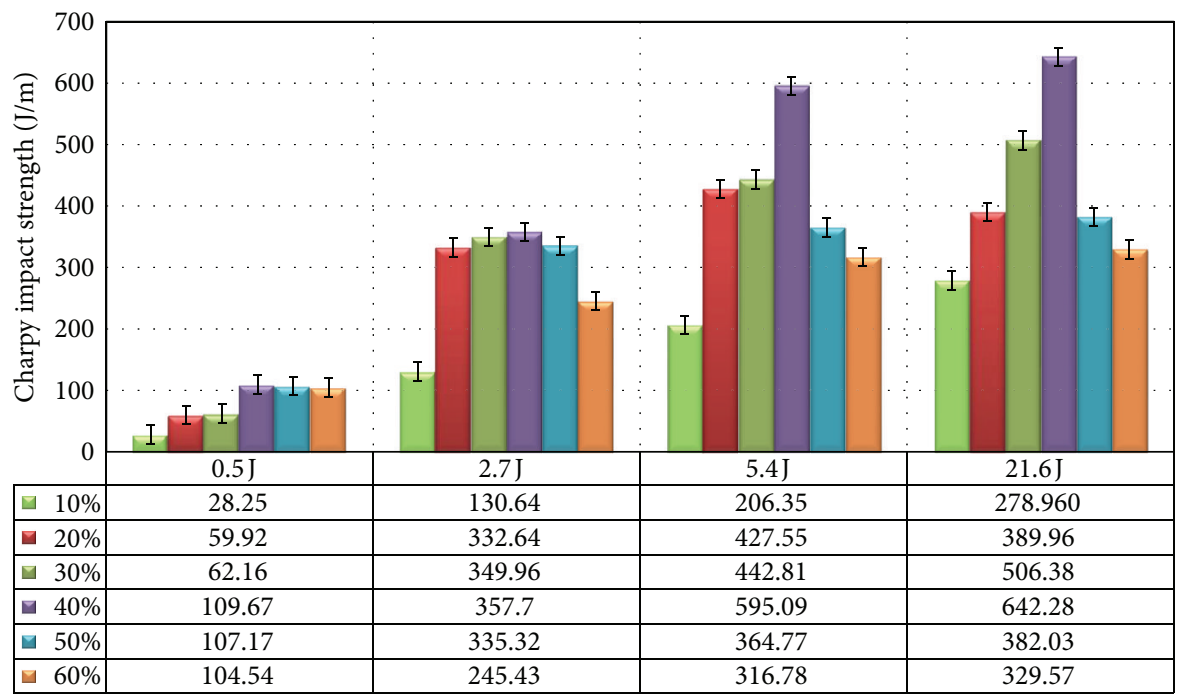

FIGURE 8: Effect of fiber content on impact strength of kenaf/PVB composites at different energy levels.

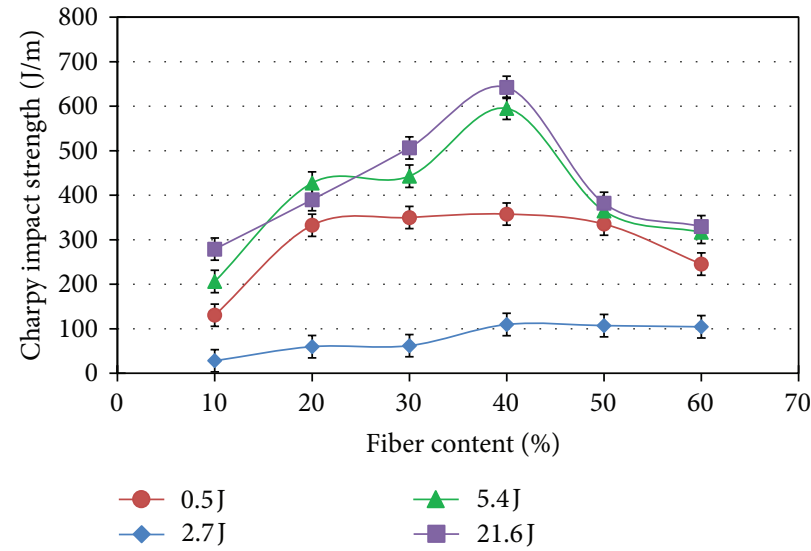

FIGURE 9: Effect of fiber content on impact strength of kenaf/PVB composites.

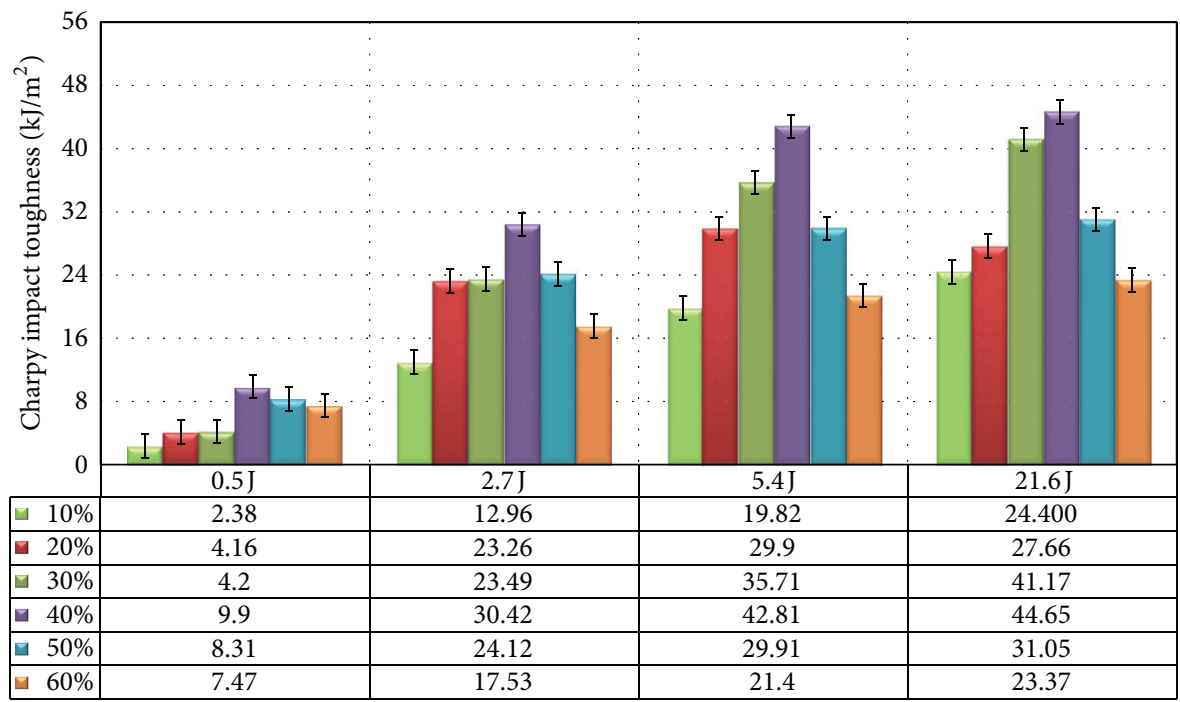

FIGURE 10: Effect of fiber content on impact toughness of kenaf/PVB composites at different energy levels. 


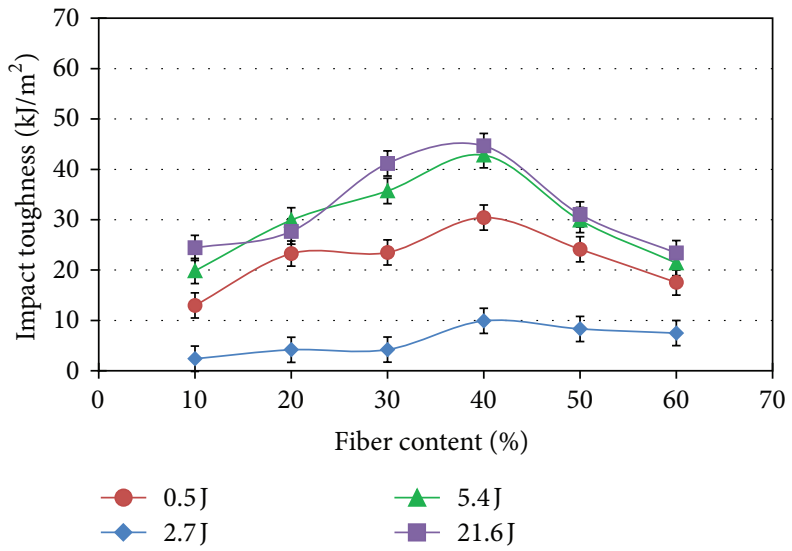

FIGURE 11: Effect of fiber content on impact toughness of kenaf/PVB composites.

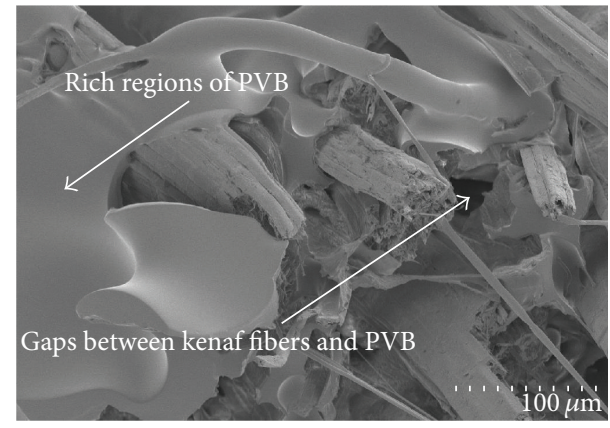

(a) $10 \%$ kenaf weight

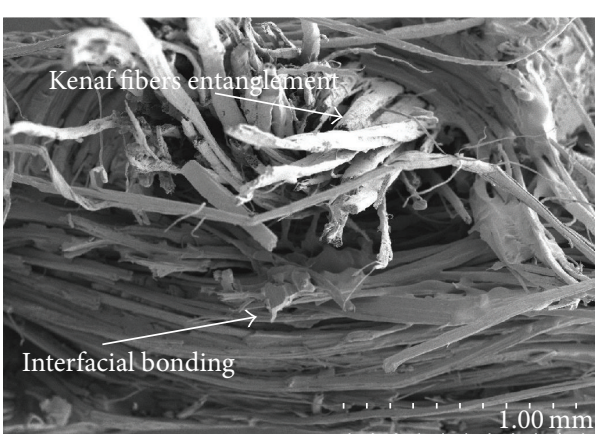

(c) $30 \%$ kenaf weight

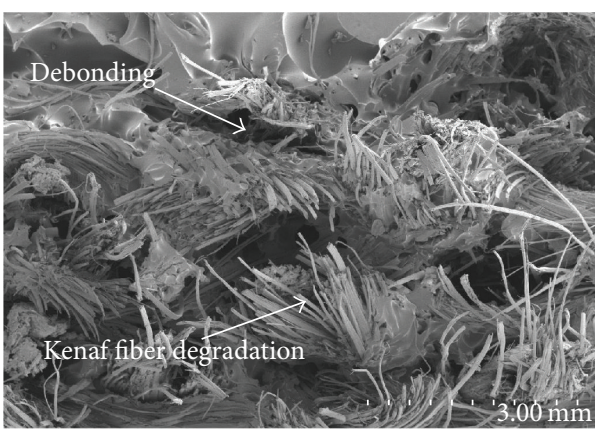

(e) $50 \%$ kenaf weight

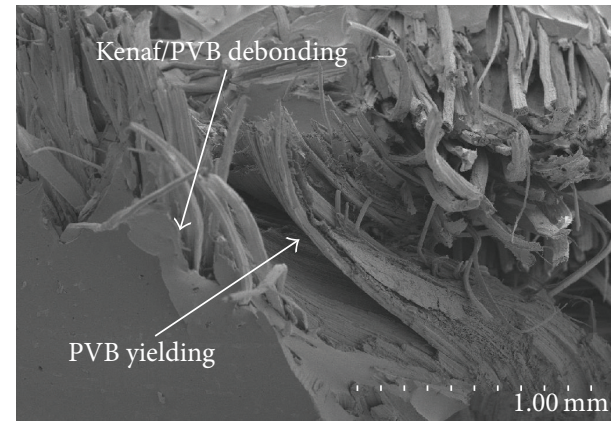

(b) $20 \%$ kenaf weight

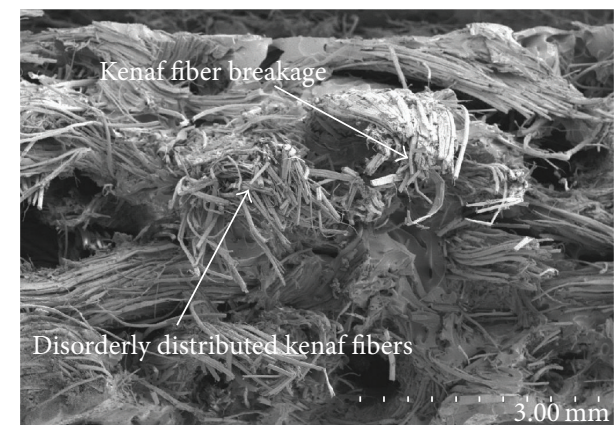

(d) $40 \%$ kenaf weight

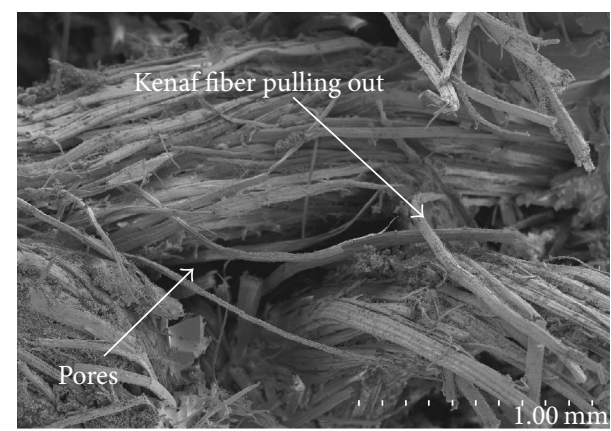

(f) $60 \%$ kenaf weight

FIGURE 12: The SEM micrographs of the Charpy impact failure surfaces of kenaf/PVB film composite. 
energy levels, while the average impact toughness of the other composites showed almost the same behavior when tested at low energy levels $(0.5 \mathrm{~J})$. As research studies have reported $[28,37]$, both fiber content and properties of the polymer are accountable for deciding the impact toughness of composites. This implies that both the effect of interlaminar delimitation and interfacial strength between fiber and matrix highly decide impact properties, especially in the case of weaving pattern as stated by others [38].

3.4. Morphological Properties. SEM photographs of all the impacted specimens $(10 \%, 20 \%, 30 \%, 40 \%, 50 \%$, and $60 \%$ kenaf fiber content) are shown in Figure 12. The fractured impact surface with $21.6 \mathrm{~J}$ energy level was selected as a representative sample for the interpretation of the degree of interfacial adhesion. It is evident that the differences in interfacial adhesion resulted in the different fracture mechanism, a combination of matrix cracking and gaps between kenaf fibers and PVB film as well as kenaf fiber breakage. These failure mechanisms agree very well with the impact damage observed by Khan et al. [39] for Jute fabricreinforced polypropylene composite and by Dhakal et al. [40] for nonwoven hemp fiber reinforced unsaturated polyester composites.

Rich regions and matrix failure were noted in the SEM image of the $10 \%$ and $20 \%$ kenaf fiber content, as shown in Figures 12(a) and 12(b), because of the lower kenaf fiber content, attributed to poor kenaf fiber distribution, hence resulting in poor energy dissipation. In $30 \%$ and $40 \%$ kenaf fiber content, an increasing trend in impact strength was found. As a result of a strong bond at the interface, the impact damage does not propagate into the vicinity of the impacted point. This was revealed by SEM micrograph in Figures 12(c) and 12 (d) which showed that the interfacial bonding between kenaf fiber and PVB film was the best among all samples, reaching the highest impact strength. However, when the kenaf fiber weight reaches beyond its threshold value, the impregnation of PVB film into the interface area is decreased and results in weak bonding between PVB film and kenaf fiber. As a result of poor kenaf fiber/PVB film adhesion, the composites could not withstand further impact loads, as noticed in the composites of $50 \%$ and $60 \%$ kenaf fiber content. Figure 12(e) shows both entanglement of kenaf fiber and kind of debonding between the kenaf fibers and PVB film, still not appearing to be to the maximum extent as shown in Figure 12(f). As a result, more shear action is observed in the interfacial zone which leads to layer-by-layer fracture of the matrix (delamination) and corroborates the observed decrease in impact strength. Also, poor wetting of the kenaf fiber surface and cohesive force between kenaf fibers may decrease with the increase in kenaf fibers content.

\section{Conclusions}

A new type of composite using kenaf fiber reinforced PVB film was fabricated with different fiber content, and its mechanical behavior was studied. Six types of laminated composites were fabricated and compared under tensile and flexural and four levels of impact conditions. It was concluded that the mechanical characteristics of the kenaf/PVB composites were variously affected by the kenaf fiber loading. $40 \%$ kenaf content composite has optimized mechanical properties, followed by $30 \%$ kenaf content, while $10 \%$ and $60 \%$ kenaf content composites have shown the weakest performance. SEM examinations of impact specimens show that the kenaf fiber content played an important role in the interfacial bonding between kenaf fiber and PVB film, which affects the mechanical properties of composites.

\section{Conflict of Interests}

The authors declare that there is no conflict of interests regarding the publication of this paper.

\section{Acknowledgments}

This work is supported by UPM under GP-IPS/2014/9438714 and GP-IPB Grant, 9415402. The authors would like to express their gratitude and sincere appreciation to the Mechanical and Manufacturing Engineering Department and Aerospace Manufacturing Research Centre of the Universiti Putra Malaysia. Their appreciation and gratitude also extend to the Ministry of Higher Education \& Scientific Research of Iraq and to the Material Engineering Department, College of Engineering, at the Al-Mustansiriya University for their scientific assistance and financial support.

\section{References}

[1] D. Saravana Bavan and G. C. Mohan Kumar, "Potential use of natural fiber composite materials in India," Journal of Reinforced Plastics and Composites, vol. 29, no. 24, pp. 3600-3613, 2010.

[2] S. D. Salman, Z. Leman, M. T. Sultan, M. R. Ishak, and F. Cardona, "Kenaf/synthetic and Kevlar ${ }^{\hat{Y}} /$ cellulosic fiber-reinforced hybrid composites: a review," BioResources, vol. 10, no. 4, 2015.

[3] S. D. Salman, Z. Leman, M. T. H. Sultan, M. R. Ishak, and F. Cardona, "Influence of resin system on the energy absorption capability and morphological properties of plain woven kenaf composites," IOP Conference Series: Materials Science and Engineering, vol. 100, no. 1, Article ID 012053, 2015.

[4] Y. A. El-Shekeil, S. M. Sapuan, and M. Haron, "Optimization of processing parameters and fiber content of cocoa pod husk fiber-reinforced thermoplastic polyurethane composites by Taguchi Method," in Applied Mechanics and Materials, vol. 564, pp. 394-399, 2014.

[5] Y. A. El-Shekeil, S. M. Sapuan, E. S. Zainudin, and A. Khalina, "Effect of fiber loading on the mechanical properties of kenaf fiber reinforced thermoplastic polyurethane composite," Key Engineering Materials, vol. 471, pp. 1058-1063, 2011.

[6] Y. El-Shekeil, S. Sapuan, M. Jawaid, and O. Al-Shuja'a, "Influence of fiber content on mechanical, morphological and thermal properties of kenaf fibers reinforced poly(vinyl chloride)/thermoplastic polyurethane poly-blend composites," Materials \& Design, vol. 58, pp. 130-135, 2014.

[7] S. Joseph, M. S. Sreekala, Z. Oommen, P. Koshy, and S. Thomas, "A comparison of the mechanical properties of phenol formaldehyde composites reinforced with banana fibres and 
glass fibres," Composites Science and Technology, vol. 62, no. 14, pp. 1857-1868, 2002.

[8] H. Ku, H. Wang, N. Pattarachaiyakoop, and M. Trada, "A review on the tensile properties of natural fiber reinforced polymer composites," Composites Part B: Engineering, vol. 42, no. 4, pp. 856-873, 2011.

[9] S. Ochi, "Mechanical properties of kenaf fibers and kenaf/PLA composites," Mechanics of Materials, vol. 40, no. 4-5, pp. 446$452,2008$.

[10] T. Nishino, K. Hirao, M. Kotera, K. Nakamae, and H. Inagaki, "Kenaf reinforced biodegradable composite," Composites Science and Technology, vol. 63, no. 9, pp. 1281-1286, 2003.

[11] B.-H. Lee, H.-J. Kim, and W.-R. Yu, "Fabrication of long and discontinuous natural fiber reinforced polypropylene biocomposites and their mechanical properties," Fibers and Polymers, vol. 10, no. 1, pp. 83-90, 2009.

[12] H. Hargitai, I. Rácz, and R. D. Anandjiwala, "Development of HEMP fiber reinforced polypropylene composites," Journal of Thermoplastic Composite Materials, vol. 21, no. 2, pp. 165-174, 2008.

[13] S. Shibata, Y. Cao, and I. Fukumoto, "Flexural modulus of the unidirectional and random composites made from biodegradable resin and bamboo and kenaf fibres," Composites Part A: Applied Science and Manufacturing, vol. 39, no. 4, pp. 640-646, 2008.

[14] S. C. Liew, Characterization of natural fiber polymer compodites for structural application [Ph.D. thesis], Faculty of Civil Engineering, Universiti Teknologi Malaysia, 2008.

[15] H. R. Rao, M. A. Kumar, and G. R. Reddy, "Hybrid composites: effect of fibers on mechanical properties," International Journal of Macromolecular Science, vol. 1, no. 1, pp. 9-14, 2011.

[16] M. J. Sharba, S. D. Salman, Z. Leman, M. T. H. Sultan, M. R. Ishak, and M. A. A. Hanim, "Effects of processing method, moisture content, and resin system on physical and mechanical properties of woven kenaf plant fiber composites," BioResources, vol. 11, no. 1, pp. 1466-1476, 2015.

[17] M. J. Sharba, Z. Leman, M. T. Sultan, M. R. Ishak, and M. A. A. Hanim, "Effects of kenaf fiber orientation on mechanical properties and fatigue life of glass/kenaf hybrid composites," BioResources, vol. 11, no. 1, pp. 1448-1465, 2015.

[18] S. D. Salman, M. J. Sharba, Z. Leman, M. T. Sultan, M. R. Ishak, and F. Cardona, "Physical, mechanical, and morphological properties of woven kenaf/polymer composites produced using a vacuum infusion technique," International Journal of Polymer Science, vol. 2015, Article ID 894565, 10 pages, 2015.

[19] ASTM, "Standard test method for tensile properties of polymer matrix composite materials," ASTM D3039/D3039M-10, ASTM International, West Conshohocken, Pa, USA, 2010.

[20] ASTM, "Standard test methods for flexural properties of unreinforced and reinforced plastics and electrical insulating materials," ASTM D790-10, ASTM International, West Conshohocken, Pa, USA, 2010.

[21] ASTM, "Standard test method for determining the Charpy impact resistance of notched specimens of plastics," ASTM D6110-10, ASTM International, West Conshohocken, Pa, USA, 2010.

[22] S. D. Salman, Z. Leman, M. T. H. Sultan, M. R. Ishak, and F. Cardona, "The effects of orientation on the mechanical and morphological properties of woven kenaf-reinforced poly vinyl butyral film," BioResources, vol. 11, no. 1, pp. 1176-1188, 2016.
[23] W. Kim, A. Argento, E. Lee et al., "High strain-rate behavior of natural fiber-reinforced polymer composites," Journal of Composite Materials, vol. 46, no. 9, pp. 1051-1065, 2012.

[24] F. M. Al-Oqla and S. M. Sapuan, "Natural fiber reinforced polymer composites in industrial applications: feasibility of date palm fibers for sustainable automotive industry," Journal of Cleaner Production, vol. 66, pp. 347-354, 2014.

[25] B. Madsen, P. Hoffmeyer, and H. Lilholt, "Hemp yarn reinforced composites-II. Tensile properties," Composites Part A: Applied Science and Manufacturing, vol. 38, no. 10, pp. 2204-2215, 2007.

[26] M. E. Ali, C. K. Yong, Y. C. Ching, C. H. Chuah, and N.S. Liou, "Effect of single and double stage chemically treated kenaf fibers on mechanical properties of polyvinyl alcohol film," BioResources, vol. 10, no. 1, 2014.

[27] B. Madsen, A. Thygesen, and H. Lilholt, "Plant fibre composites-porosity and stiffness," Composites Science and Technology, vol. 69, no. 7-8, pp. 1057-1069, 2009.

[28] T. Huber, S. Bickerton, J. Müssig, S. Pang, and M. P. Staiger, "Flexural and impact properties of all-cellulose composite laminates," Composites Science and Technology, vol. 88, pp. 9298, 2013.

[29] S. Shibata, Y. Cao, and I. Fukumoto, "Press forming of short natural fiber-reinforced biodegradable resin: effects of fiber volume and length on flexural properties," Polymer Testing, vol. 24, no. 8, pp. 1005-1011, 2005.

[30] A. C. de Albuquerque, K. Joseph, L. Hecker de Carvalho, and J. R. M. d'Almeida, "Effect of wettability and ageing conditions on the physical and mechanical properties of uniaxially oriented jute-roving-reinforced polyester composites," Composites Science and Technology, vol. 60, no. 6, pp. 833-844, 2000.

[31] Z. Jiang, F. Chen, G. Wang et al., "Bamboo Bundle Corrugated Laminated Composites (BCLC). Part II. damage analysis under low velocity impact loading," BioResources, vol. 8, no. 1, pp. 923932, 2013.

[32] V. Tita, J. de Carvalho, and D. Vandepitte, "Failure analysis of low velocity impact on thin composite laminates: experimental and numerical approaches," Composite Structures, vol. 83, no. 4, pp. 413-428, 2008.

[33] R. Joffe and J. Andersons, "13-Mechanical performance of thermoplastic matrix natural-fibre composites," in Properties and Performance of Natural-Fibre Composites, K. L. Pickering, Ed., pp. 402-459, Woodhead Publishing, 2008.

[34] D. C. O. Nascimento, S. N. Monteiro, and L. C. Motta, "Characterization of the toughness of piassava fiber reinforced epoxy matrix composites by Izod impact test," in Proceeding of the Characterization of Minerals, Metals \& Materials-TMS Conference, pp. 1-7, San Francisco, Calif, USA, February 2009.

[35] Y. A. El-Shekeil, S. M. Sapuan, and M. W. Algrafi, "Effect of fiber loading on mechanical and morphological properties of cocoa pod husk fibers reinforced thermoplastic polyurethane composites," Materials \& Design, vol. 64, pp. 330-333, 2014.

[36] R. Wirawan, S. M. Sapuan, K. Abdan, and R. Yunus, "Tensile and impact properties of sugarcane bagasse/poly (vinyl chloride) composites," Key Engineering Materials, vol. 471-472, pp. 167172, 2011.

[37] S. Karimi, P. M. Tahir, A. Karimi, A. Dufresne, and A. Abdulkhani, "Kenaf bast cellulosic fibers hierarchy: a comprehensive approach from micro to nano," Carbohydrate Polymers, vol. 101, no. 1, pp. 878-885, 2014.

[38] N. M. Aly, M. A. Saad, E. H. Sherazy, O. M. Kobesy, and A. A. Almetwally, "Impact properties of woven reinforced sandwich 
composite panels for automotive applications," Journal of Industrial Textiles, vol. 42, no. 3, pp. 204-218, 2013.

[39] J. A. Khan, M. A. Khan, R. Islam, and A. Gafur, "Mechanical, thermal and interfacial properties of jute fabric-reinforced polypropylene composites: effect of potassium dichromate," Materials Sciences and Applications, vol. 1, no. 6, pp. 350-357, 2010.

[40] H. N. Dhakal, Z. Y. Zhang, N. Bennett, and P. N. B. Reis, "Lowvelocity impact response of non-woven hemp fibre reinforced unsaturated polyester composites: influence of impactor geometry and impact velocity," Composite Structures, vol. 94, no. 9, pp. 2756-2763, 2012. 

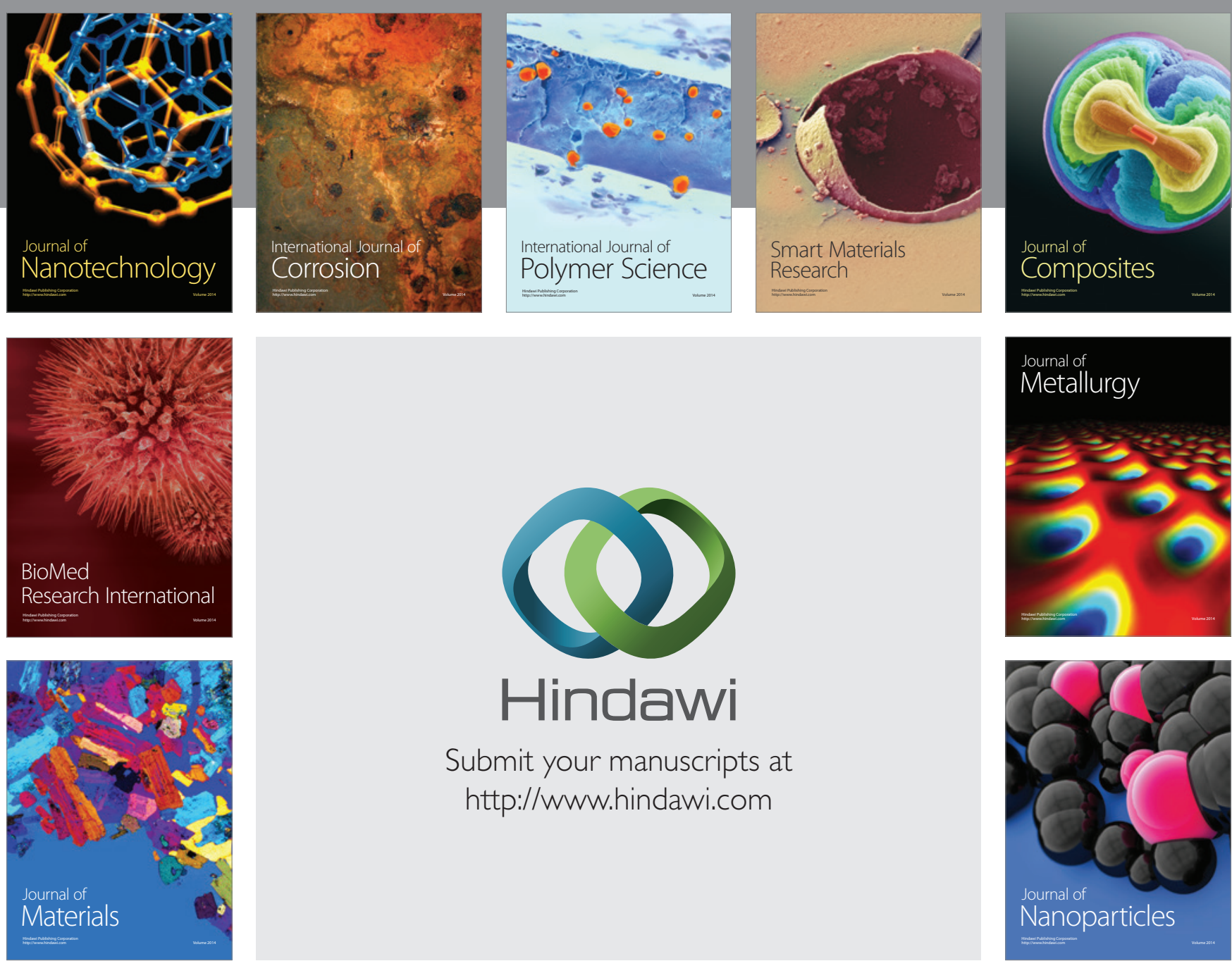

\section{Hindawi}

Submit your manuscripts at

http://www.hindawi.com

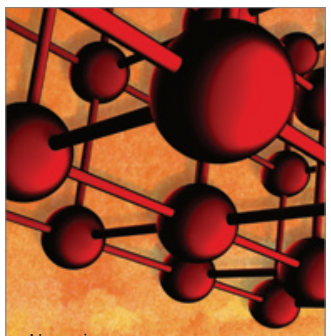

Materials Science and Engineering
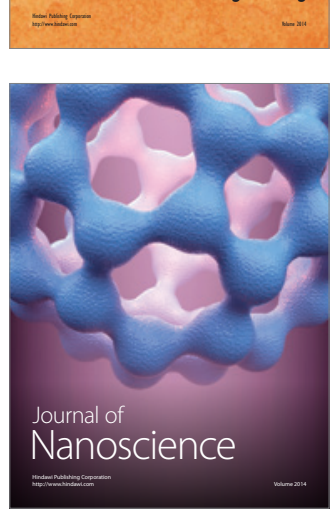
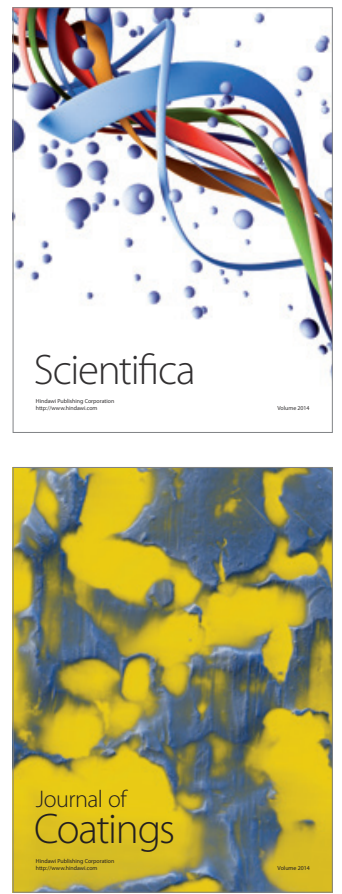
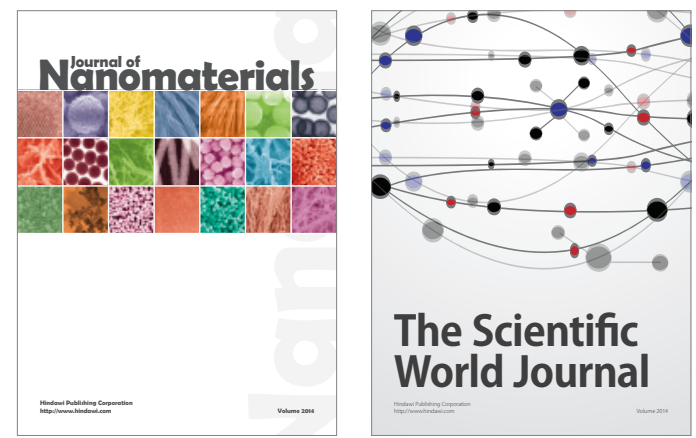

The Scientific World Journal
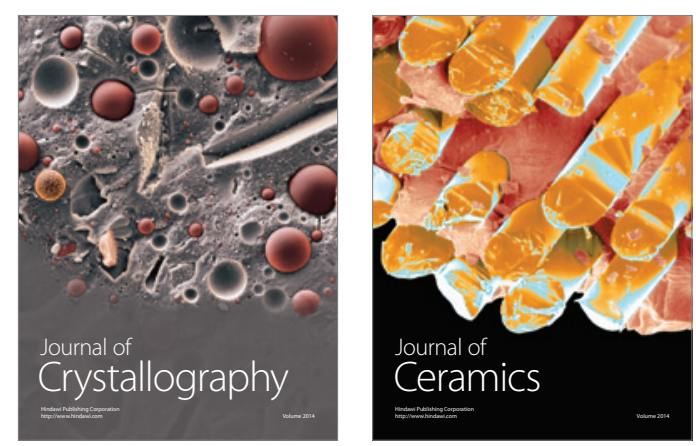
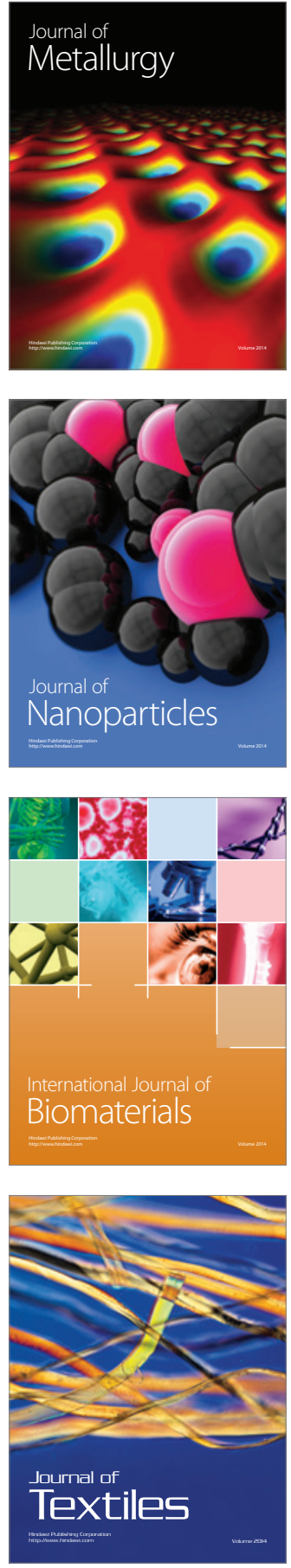